\title{
Counselling al final de la vida y en el duelo
}

\section{End of life and grief counselling}

\author{
José Carlos Bermejo \\ Universidad Pontifica Comillas
}

\begin{abstract}
Resumen: Todos antes o después nos encontraremos con procesos de muerte. En este trabajo se revisa un modo de acompañar al final de la vida y en el duelo, desde la relación de ayuda o counselling. Se define lo que significa acompañar el morir y el duelo, haciendo hincapié en las competencias que los profesionales de la salud necesitan para acompañar estos momentos delicados de la vida humana. Se profundiza en lo que significa acompañar a adjetivar la muerte y acompañar a vivir la muerte biográfica. También se repasan algunos desafíos en el acompañamiento del morir desde la perspectiva de la ética del cuidado y desde la perspectiva social. Por último, se revisa un modo de apropiación del morir, como es la promoción del testamento vital.
\end{abstract}

Palabras clave: Proceso de muerte; acompañamiento al final de la vida; duelo; counselling; profesionales de la salud.

\begin{abstract}
All of us will face a dying process sooner or later. This paper discusses a way to accompany people during the end of life and grief process based on counselling. It is defined what it means to accompany the dying and mourning process, with special emphasis on the competencies that healthcare professionals need to attend these delicate moments of human life. The paper elaborates on what it means to accompany describing death and to accompany living biographical death. Some challenges in accompaniment of dying are also reviewed from the ethics of care perspective and from the social perspective. Finally, a mode of appropriation of death, the promotion of living will, is reviewed.

Keywords: Dying process, end-of-life accompaniment, grief, counselling, health care profesionals.
\end{abstract}

\section{Counselling en salud}

Los seres humanos, antes o después, nos las vemos con el morir. A veces, de manera súbita, en otras ocasiones, como proceso de ir perdiendo y acompañando a quienes amamos o a quienes cuidamos, como profesionales, familiares o voluntarios.

José Carlos Bermejo es Director General del Centro San Camilo.

La correspondencia sobre este artículo debe enviarse al autor al Centro de San Camilo. Sector Escultores 39, 28769 Tres Cantos, Madrid. E-mail: jcbermejo@humanizar.es

(cc) BY-NC-ND Este es un artículo Open Access bajo la licencia CC BY-NC-ND. 
Acompañar viene del latín: cum-panis. Su significado tiene relación simbólica con lo que podríamos expresar así: comer pan juntos, sentarse a la mesa emocional y espiritual del enfermo y su familia e intercambiar cuanto hay en ella: sentimientos, deseos, preocupaciones, esperanzas...

Acompañar al final de la vida y en el duelo pasa por hacer un camino con el que sufre, yendo a su ritmo, acompasando las notas musicales del mundo interior. La psicología nos permite tomar conciencia de los elementos fundamentales del acompañamiento con la expresión relación de ayuda o counselling. Los profesionales de la salud necesitan competencias para acompañar en estos momentos delicados de la vida humana. A ellos se les está prestando una atención creciente en los últimos años por ofrecer los recursos en términos de actitudes y habilidades para un acompañamiento oportuno, aunque aún es insuficiente (Bermejo, Magaña, Villacieros, Carabias, y Serrano, 2012; Bermejo, Villacieros, Magaña, 2017).

En efecto, ser profesional de la salud no solo significa poseer una serie de conocimientos propios del arte de la medicina, psicología, enfermería, rehabilitación, etc. Es mucho más. Es un arte. Y un arte se aprende con la experiencia, pero también sometiendo el propio estilo relacional al cuestionamiento sobre el modo mejor de ser efectivos y humanos a la vez (Bermejo, Carabias y Villacieros, 2012; Bermejo, Villacieros y Carabias, 2013; Villacieros, Olmos, Bermejo, 2017).

Estoy firmemente convencido de la necesidad de desaprender estilos relacionales que hemos interiorizado espontáneamente debido al modelado o imitación de nuestros pares. Estos no siempre son los mejores. Muchos estilos de intervención en salud son defensivos, otros están marcados por la dificultad emocional que nos genera la situación, otros por la complejidad ética, otros por nuestras propias experiencias personales.

Enseñar counselling en salud para mí es una tarea apasionante. Significa mediar entre el profesional y su propio cuestionamiento sobre su modo de intervenir. Y así, hay muchos que se sienten interpelados en el ámbito de la cordialidad que despliegan o no despliegan en la relación; otros se dan cuenta de que tienden a moralizar sin desearlo; otros descubren que su estilo es interrogatorio en exceso; no falta quien se da cuenta de que responde siempre con tópicos y frases hechas. Y descubrir esto es un modo de crecer, de cualificar la relación, de hacerla más satisfactoria y más humana.

Por otro lado, hay que tener en cuenta que siempre hay más personas en duelo, afectadas por la muerte del otro, que personas que mueren. Cada muerte afecta a un grupo importante de personas que sufren por la pérdida, ya antes de que se produzca, cuando esta no es de manera repentina.

Y, sin embargo, la reflexión sobre el duelo, sobre la pérdida de un ser querido, sobre el modo de acompañar a quien vive este sufrimiento, es aún bastante escasa. De alguna manera, de la mano de la muerte, el duelo constituye uno de esos temas tabú sobre los que tampoco somos educados a vivirlo sanamente si no es por la fuerza de la experiencia próxima cuando esta sea capaz de transmitirnos alguna clave.

¿Es posible pensar que la muerte del otro, además de desgarro, puede enseñar a vivir y humanizarnos? ¿Hay acaso algo de positivo que podamos encontrar en la muerte o en el proceso del morir o del acompañamiento a quien vive su propia muerte -si no se la expropian-, que nos pueda aportar algo para ser más felices? ¿No es la muerte de un ser querido una pérdida dolorosa que, sobre todo, nos desgarra y nos pone en crisis? ¿La intervención psicológica ayuda y previene de algo?

Sí. Lo es. Y sin embargo, el morir y la muerte reclaman verdad y verdades que aprender y pueden contribuir a humanizarnos.

La muerte nos pone irremediablemente ante el misterio de la vida. Nos impone silencio, y el silencio vacío, reflexión inevitable. Y, de alguna manera, nos hace a todos filósofos, pensadores sobre el sentido último de la vida, de las relaciones, del amor. Pero no es un pensar cualquiera el que desencadena la muerte, sino un pensar sintiendo intensamente, un vivir ante el enigma que nos embaraza a todos de posibilidad de engendrar y parir sentido. La muerte, así, puede enseñar a vivir y humanizarnos y acompañar en los procesos desde la psicología, representa un deber ético y oportunidad de generar salud biográfica.

Acompañar en el morir puede enseñar a vivir, porque reclama valores que fácilmente pueden estar relegados en la cotidianeidad, valores evocados más por el sentimiento que por la razón, valores que reclaman relación y acompañamiento.

Ese no saber qué decir propio del acompañamiento al final de la vida y en el duelo es tan significativo como que revela nuestra identidad de limitación, de vulnerabilidad, de pobreza; revela el valor de nuestra presencia 
silenciosa, el valor del abrazo y de la mano tendida, de la mirada y de la caricia sincera; revela el poder de lo pequeño, de lo sencillo, la necesidad de lo simbólico para sobrevivir, para seguir viviendo.

\section{Acompañar a adjetivar la muerte}

Si una característica puede tener el morir para que este merezca el calificativo de digno es un morir apropiado.

El ideal de muerte sentido hoy mayoritariamente como un ideal no consciente reclama un morir repentino que nos impediría vivir el morir. El empeño de la ciencia, en cambio, lucha por postponerlo y promover una vida más larga. Esta vida prolongada conlleva también la posibilidad de vivir más tiempo conviviendo con patologías largas, así como con otras degenerativas.

En todo caso, el ser humano, a diferencia de los animales, tiene la posibilidad de vivir el morir si no es expropiado de esta posibilidad. Esta es la primera característica, pues, que debería tener una muerte digna: una muerte apropiada, no expropiada como nos hace ver de manera tan clara Tolstoi en La muerte de Ivan Illich (1970, p.62).

Morir dignamente consiste en hacer el esfuerzo por adjetivar el proceso personal y acompañar desde el entorno a adjetivar con semejantes palabras el final. Cada persona, así, podría imaginar su propio proceso describiéndolo con calificativos personales, propios, que hicieran de este momento de su existencia un momento tan importante que es, definitivamente, el último.

Una muerte sería tanto más digna cuanto más fuera dicha por el sujeto y las personas a las que más le afecta. Una muerte dicha es aquella en la que hay espacio para la voz, para las palabras en torno al morir, donde se consiga escuchar lo que se dice y lo que no se dice, así como lo que hace decir aquello que se dice y lo que hace no decir aquello que no se dice.

Una muerte digna sería aquella que mereciera el adjetivo de bella, pero no en un sentido idealizado, sino una muerte en la que la persona viva hasta el último instante, que no muera antes, que no le vivan los demás o le mueran los demás.

Una muerte adjetivada sería aquella en la que los sujetos se sintieran contentos, es decir, salvados por la muerte, porque la muerte de la muerte sería la muerte del amor y de la solidaridad. Es la muerte la que da sentido último a nuestra vida, y lo es si somos capaces de llenar (con-tenti) de contenidos y de comunión nuestras relaciones.

Promover una muerte adjetivada significa hacer lo posible porque la muerte lo sea de artesanos del morir, que el morir sea una dimensión de la vida a la que ya nos hayamos ido entrenando a lo largo de la misma, aprendiendo a perder y a integrar progresivamente nuestra condición de finitud.

Hablar de muerte digna significa trabajar porque la persona se gobierne a sí misma en el máximo de sus posibilidades, gobernando así el espacio (físico, personal, afectivo, etc.) que le rodea en los últimos meses o días, hasta donde la naturaleza y la limitación personal lo permita.

Una muerte humanizada es aquella donde se pueda desarrollar la legítima rareza de cada uno, donde puedan ser expresados de manera adecuada los sentimientos, los deseos, las compañías deseadas o no, las expectativas...

Una muerte digna sería aquella que se convierta en verdadera experiencia de amor porque experiencia de muerte la hace solo el que ama. De la muerte deberíamos hablar como hablan los enamorados, que aman la vida porque es limitada, porque desean sacarle el máximo jugo y gozo a cada instante.

La muerte debería ser un ejercicio de aprendizaje, de arte, porque una sola cosa es el ars vivendi y el ars moriendi cuando se supera la idea de que el morir sea un instante y se concibe como un proceso en el caminar humano hacia la realización de lo que somos y lo que estamos llamados a ser.

Sería más humana aquella muerte que pudiera ser narrada. Porque, en el fondo, de aquello que no podemos hablar, lo mejor que se puede hacer es... narrarlo (Malherbe, 1993). Una muerte narrada permite ser adjetivada por uno mismo, por los seres queridos. No encuentra explicación a los porqués, pero se llena de palabras al hablar de los cómo. 
En el fondo, una muerte adjetivada sanamente recibiría el nombre de muerte elegante, porque sería a la medida de la capacidad responsable del propio elegir (=elegante) personal. Considerar la vida como un don, para quien así la interpreta, no debería llevarnos a pensar que su fin tenga que ser dejado exclusivamente a los juegos de azar de la caprichosa naturaleza no racional.

Una muerte adjetivada podría ser vivida así como la vida de un archipiélago, que se caracteriza justamente por estar unido por aquello que separa.

La muerte adjetivada se convertiría así en experiencia de misterio en lugar de simple problema que gestionar. El misterio no es algo que esté fuera de nosotros y tenga solución. Eso es el problema. El misterio está dentro de nosotros, nos envuelve y no tenemos más posibilidad que vivirlo. Vivirlo humanamente comportará la máxima expresión de salud de una persona, que se traduce en la meditatio mortis, que no será la desagradable obsesión por la misma, sino la humana comprensión del valor último de la vida a la vista de su fin.

\section{Acompañar a vivir la muerte biográfica}

Acompañar a vivir la última etapa de la vida supone considerar la muerte como el fin de una biografía humana reconociendo lo específicamente humano, no solo el fin de una biología. Porque la muerte reconocida únicamente como el fin de una biología da paso a la deshumanización y a la despersonalización y nos aproxima a la muerte de los animales.

Morir puede ser triste, pero morir los unos para los otros antes de morir es mucho más triste. Y esto es lo que sucede cuando tanto las palabras como el silencio imponen su lado trágico.

Queriendo evitar el drama de la verdad, caemos a veces en la soledad y el abandono en la proximidad de la muerte. El silencio, que puede ser un saludable correctivo a la retórica banalizante de las palabras y pudiera ofrecer quizá el consuelo que viene de la muda solidaridad, en estas condiciones es solo un vacío de palabras. Comunica al enfermo incurable que ya no es alguien con quien se pueda comunicar. Es decir, le comunica que socialmente puede darse por muerto y que en realidad solo queda asistir al fin de una biología.

El encuentro en la verdad, en cambio, el diálogo con el enfermo al final de la vida, basado en la autenticidad, genera libertad. Produce cierto pánico, pero da paz al superviviente y serenidad a quien escribe el último capítulo de su vida.

Tanto familiares como profesionales pueden llegar a sentirse bloqueados y culpables por estar sanos junto a un ser querido en proceso de muerte. Al fin, es él el que va a morir. Comunicar con el enfermo en este estado de angustia resulta difícil. Es como si todo lo que se dice sonara un poco a incoherencia y a pobreza o artificialidad. Es incómodo y doloroso estar junto a la persona al final de la vida; es como sentirse acusados por el silencio del enfermo de no hacer nada para curarle.

Sin embargo, superadas las barreras, el encuentro en la verdad ayuda al enfermo con enfermedad avanzada a elaborar su duelo anticipatorio por lo que prevé y experimenta que está perdiendo, y ayuda al ser querido o profesional a elaborar el dolor que producirá la pérdida y que se empieza a elaborar de manera anticipada también antes de que acontezca.

Reconocer la experiencia del duelo y de sus diferentes tipos (Bermejo, 2009), constituye un modo de acompañar a hacer de la experiencia de morir un acto biográfico en el que la vida se narra y recibe una nueva luz de sentido.

En efecto, acompañar a quien narra su vida está cargado de contenido simbólico, porque narrar la propia vida supone un verdadero esfuerzo. Narrar es poner en perspectiva acontecimientos que parecen accidentales. Es distinguir en el propio pasado, lo esencial de lo accesorio, los puntos firmes. Contar la propia vida permite subrayar momentos más importantes, e, igualmente, minimizar otros. Se puede, en efecto, gastar más o menos tiempo en contar un acontecimiento que en vivirlo. Para contar, es necesario escoger lo que se quiere resaltar, y lo que se quiere poner entre paréntesis. El relato crea una inteligibilidad, da sentido a lo que se hace. Narrar es poner orden en el desorden. Contar la propia vida es un acontecimiento de la vida, es la vida misma, que se cuenta para comprenderse. 
Narrar no es fabular. Contar los acontecimientos que se han sucedido en la vida permite unificar la dispersión de nuestros encuentros, la multiplicidad disparatada de los acontecimientos que hemos vivido. Podríamos decir en el fondo, que relatar la vida le da un sentido.

Los acompañantes de las personas al final de la vida, si han conseguido entablar la relación basada en una buena dosis de autenticidad y sencillez, reconocen con mucha frecuencia cuán importante y enriquecedor ha sido para ellos acompañarlos.

Los enfermos avanzados suelen dar algo muy importante: la capacidad de aceptar la muerte y de dejarse cuidar en medio del sentimiento de impotencia, dando mucha importancia al significado de la presencia y de la escucha del mundo interior, así como la servicialidad para satisfacer todas las necesidades.

El cuidador desearía más bien tener algo que dar, algo con lo que evitar lo que se presenta como inevitable. Y el sentimiento de impotencia le embarga con frecuencia. Pues bien, podríamos decir que cuando un cuidador o un acompañante toca su propia sensación de impotencia es cuando está más cerca de quien sufre. Mientras nos negamos a aceptar nuestros límites, mientras no asumimos nuestra parte de impotencia, no podemos estar realmente cerca de quienes van a morir.

Quizás por eso, junto al que se encuentra al final de la vida, podemos aprender a desaprender las tendencias a querer dar siempre (razones, palabras, cuidados...), y comprender la importancia de dejarse querer y cuidar, la importancia y elocuencia del silencio y de la escucha.

Aprender junto al que vive su última etapa y muere su biografía supone ejercer el arte de decir adiós. Hay personas que no saben despedirse, que niegan las despedidas, que las posponen o que las viven solo como experiencia negativa, con reacciones poco constructivas.

Aprender a despedirse significa ser capaces de verbalizar con quien se va, el significado de la relación (a veces con la necesaria solicitud de perdón por las ofensas), y asegurar a quien se va que seguirá vivo en el corazón del que queda. Expresar los sentimientos, aprender a nombrarlos abiertamente constituye no solo una posibilidad de drenar emocionalmente y liberarse de buena parte del sufrimiento producido por la separación, sino también dar densidad y significado a la separación, escribir el último capítulo del libro de la vida de una persona y levantar acta de la propia muerte.

Esta ética del cuidado y de la relación al final de la vida contribuirá a humanizar la bioética más circulante en torno especialmente a la autonomía del ser humano, sin caer en un superficial autonomismo o exaltación del individualismo en la gestión del propio morir.

\section{Algunos desafíos en el acompañamiento del morir}

Desde una perspectiva de la ética del cuidado, así como desde la perspectiva social, es particularmente relevante conocer algunos síndromes o situaciones que tienen lugar en el proceso de morir y que reclaman un cuidado moral adecuado.

Nos referimos a la claudicación familiar, al síndrome del hijo de Bilbao, al duelo anticipatorio, al síndrome de Diógenes, al síndrome de Lázaro, a la codependencia, y al burn-out, entre otros.

Entendemos por claudicación familiar (Bover, Santancreu, Pons, Mestre, Gallo, y Adrover, 2002; Stenberg, Ruland y Miaskowski, 2010) la incapacidad de los miembros de la familia para ofrecer una respuesta adecuada a las múltiples demandas y necesidades del paciente. Se produce cuando todos los miembros del grupo familiar claudican a la vez y es consecuencia de una reacción emocional aguda de los familiares a cargo del enfermo, y en especial del cuidador. Esta situación reclama la responsabilidad ética de la comunidad de salir al paso de la vulnerabilidad del paciente y de la familia.

El síndrome del hijo de Bilbao (Gómez Sancho, 2005) es la reacción emocional y comportamental de un familiar (habitualmente hijo/a) que vive en otra ciudad y que acude al final de la vida, que no suele participar de los cuidados del ser querido y que, a la vista del familiar moribundo reacciona con dificultad en la aceptación de la muerte, con exigencias y órdenes para resolver a su manera lo que otros no han podido, culpabilizando a los cuidadores y al equipo de la situación. Esta situación reclama la responsabilidad de los cuidadores -profesionales o no- de comprender la dinámica para evitar la moralización y salir al paso de las necesidades de todos los miembros de la familia. 
El duelo anticipatorio consiste en el dolor que experimentan familiares y cuidadores antes de que se produzca el fallecimiento (Bermejo y Magaña, 2014). Bien elaborado contribuye a un duelo saludable tras la muerte de la persona. Esta situación reclama la responsabilidad ética de acompañar competentemente a la persona que se duele próxima la pérdida del ser querido.

El síndrome de Lázaro (Sahni, 2012) se produce cuando la unidad familiar (o un miembro de ella) ya estaban emocionalmente preparados -e incluso organizados- para vivir sin el ser querido que se ve que empeora y se aproxima a la muerte y, sin esperarlo, se produce una mejoría del moribundo, produciéndose desajustes emocionales y sociales en la familia. Esta situación reclama asimismo la responsabilidad ética de los profesionales y cuidadores de acompañar emocionalmente a los afectados.

El síndrome de la codependencia consiste en el riesgo de un cuidador de depender de la persona dependiente a la que cuida. Se manifiesta en indicadores como creerse indispensable, incapacidad para delegar, no fiarse de otros cuidadores, no tolerar los límites propios y ajenos, no aceptar a otros cuidadores, poner todo el sentido de la vida en el cuidado, etc. Esta situación reclama la responsabilidad ética de los profesionales de ayudar a los cuidadores en riesgo, señalando un sano equilibrio entre cuidado y autocuidado, así como el reclamo de la libertad en contraposición de la dependencia (Gonzalos y Magos, 2012).

El síndrome del burn-out es el síndrome de agotamiento, de despersonalización (hacia la persona cuidada) de reducida realización personal, que puede aparecer en personas que trabajan en contacto con personas (Maslach, 1982). Esta situación reclama igualmente la responsabilidad ética del autocuidado de los profesionales y cuidadores de los seres queridos al final de la vida, así como el cultivo de las motivaciones intrínsecas que puedan prevenir llegar a tal situación (Sandrin, Calduch-Benages y Torralba, 2007).

Una particular atención a este tipo de aspectos psicológicos y éticos la manifiesta la filosofía de los cuidados paliativos.

En efecto, los cuidados paliativos, cada vez más extendidos, constituyen esa dimensión femenina de la medicina que ha hecho la paz con la muerte y que se dispone a cuidar siempre, aunque curar no se pueda. La particular atención a la familia (y no solo al enfermo), la blandura (humanización) de las normas de las instituciones que desarrollan tales programas, la atención delicada al control de síntomas, al soporte emocional y espiritual y el reconocimiento del peso específico de la relación y de la responsabilidad del individuo en su propia vida, dibujan un nuevo panorama menos paternalista de la medicina y más en sintonía con la integración de nuestra condición de seres mortales.

Asistimos hoy al reto de promover la medicina paliativa, así como al de promover una creciente y responsable participación de los profesionales de la salud en la reflexión sobre la cultura paliativa en la sociedad en general. De este modo contribuiríamos, sin lugar a dudas, a humanizar el morir.

\section{Acompañar y promover el Testamento Vital}

Uno de los modos de contribuir a la humanización del morir, a la apropiación del morir, es la promoción del testamento vital (Bermejo y Belda, 2011). Así lo hizo la Conferencia Episcopal Española, por ejemplo, cuando en septiembre de 1989 promovió una iniciativa (casi campaña) con la difusión de un texto en formato cartulina apropiada para llevarlo en la billetera, con el título "Testamento Vital”.

Su origen procede de la Asociación de Profesionales Sanitarios Cristianos que, en sus II Jornadas Nacionales, celebradas en Zaragoza el año 1988, entre sus conclusiones manifestó la necesidad de la formación de los Profesionales Sanitarios en asuntos como la eutanasia y la muerte digna.

La historia posterior ha llevado a que en España el testamento vital haya pasado a ser una cuestión regulada por la ley (Ley 41/2002, 2002, art. 11) y reflexionada por instancias bioéticas.

Los testamentos vitales, instrucciones previas o voluntades anticipadas son documentos escritos en los que un paciente capaz expresa sus deseos, preferencias y decisiones respecto a los tratamientos que desea recibir o no al final de su vida, cuando no esté en condiciones de decidir (Barrio y Simon, 2009).

En general, los documentos de instrucciones previas recogen la declaración acerca de cómo el sujeto desea que se desarrolle el proceso de morir, y expresa el deseo de que no se administren medidas de soporte vital 
cuando no hay expectativas de recuperación, a la vez que se manifiesta el deseo de recibir cuidados y tratamientos para paliar el dolor y los síntomas más desagradables. Normalmente supone nombrar a un representante para que, llegado el momento, manifieste la voluntad del sujeto. Algunos autores piensan que puede ser particularmente importante cuando se prevé una disminución de la capacidad del sujeto para tomar decisiones (Marcos del Cano, 2001).

No falta quien mantiene sus dudas sobre el hecho de que la promoción del testamento vital sea un camino humanizador. Hay quien piensa más bien que es una especie de "testamento de desconfianza" (Sandrin, 2006, p. 557) en los profesionales que se ocuparán de nosotros si perdemos la conciencia, o un camino abierto a la promoción de una cultura pro-eutanasia.

Lejos de esta opinión, a nuestro juicio, la conciencia de la propia finitud, el diálogo sobre la propia muerte, la indicación a familiares, amigos y futuros profesionales, de nuestra escala de valores y los límites a los que estamos expuestos cuando la medicina se desliza a un paradigma biologicista y se convierte en tecnocracia, es un modo noble de ejercer la responsabilidad y de humanizar el final de la vida y, por ende, el ejercicio de la medicina.

Ya Hipócrates, en su obra Sobre el arte, aconseja al médico que "mitigue el sufrimiento del enfermo, atenúe la intensidad de sus dolencias y desista de tratar a aquellos a los que les ha vencido su enfermedad, reconociendo ante tales casos la impotencia de la medicina". El objetivo de la medicina es, para Hipócrates, "disminuir la violencia de las enfermedades y evitar el sufrimiento a los enfermos, absteniéndose de tocar a aquellos en quienes el mal es más fuerte y están situados más allá de los recursos del arte". En estas latitudes europeas, quien se mueve en el mundo de la atención al final de la vida, sabe que no es este el paradigma que impera. No por mala voluntad de los galenos, sino por el mismo dinamismo de la ciencia y la cultura de la que participamos todos: profesionales, pacientes, familiares...

Algunos creen que el testamento vital es un modo de exaltar la autonomía de la persona (Beauchamp y Childress, 1999). Más bien se trata de un modo saludable de ejercer la propia responsabilidad humana frente al propio morir. Un modo saludable de mirar a la cara a la "hermana muerte corporal", un modo de pensar la salud en términos biográficos y de responsabilidad, no meramente biológicos.

La filosofía que subyace en la legislación al respecto es la de proteger la autonomía del enfermo, y su antecedente más próximo en este sentido es la puesta en marcha del consentimiento informado o lo que es lo mismo, tomar en cuenta la voluntad del paciente antes de aplicar cualquier tratamiento médico. Ocurre que al igual que el consentimiento informado, el documento de instrucciones previas puede convertirse en un papel, un acto burocrático más, sin que su elaboración lleve al diálogo y la reflexión compartida.

En el fondo, humanizar el morir es la clave del documento de instrucciones previas o testamento vital. Un empeño por promover una cultura de la responsabilidad con la propia condición de finitud debe caracterizar a quien se tenga por mortal y no quiera situarse ante semejante verdad mediante la negación.

Sin duda, la medicina, la cultura médica que construimos todos los seres humanos, llamada también a atender humanamente el final de la vida, no solo a luchar contra la muerte, está ante el reto de sanar las enfermedades que posiblemente padece para humanizar el morir. El objetivo es sanar el morir (Bermejo, 2009) de las posibles patologías de las que puede ser víctima una tendencia no modulada por la responsabilidad individual y colectiva ante el final.

Mirar atrás y adelante lo justo para vivir con plena conciencia de la realidad, esa sería la cuestión. Revivir lo pasado para aprender/aprehender el ahora. Proyectar lo que vendrá en su justa medida, anticipando lo que quizá en su momento no podremos decidir. Habremos de plantear nuestra vida como un todo integrado, del que no somos señores absolutos, y sin embargo sí artífices en libertad, y por tanto responsables de gobernar lo que de nosotros depende con rectitud, en función de los valores en que creemos. Sin licencias ni escondrijos, sin trampas ni cartón. Lo que hacemos o dejamos de hacer es signo de que creemos, elegimos, conducimos y vivimos con todas las de la ley.

De este modo, con estos pensamientos, elaborar el testamento vital es también un acto trascendente. Trascendente por el sentido con el que nos lo planteamos. Es un acto que nos obliga a tomar conciencia, a vivir con los ojos bien abiertos ante la verdad existencial, ante la realidad del final de la vida. Trascendente también porque atraviesa la barrera de lo que controlamos: después de haberlo intentado todo con la voluntad y la libertad que hemos recibido, damos un paso más. 
Realizar este acto nos obliga a replantearnos el sentido vital, y también el lugar que ocupan en nuestra vida la responsabilidad y la confianza supremas. Creemos que el ser humano puede afirmarse voluntariosamente hasta un determinado punto en el cual solo adquiere sentido confiar que llegamos a buenas manos, a buen puerto. Y conforme a esto que pensamos en relación al final de la vida, así vivimos. Esto que sirve para el final de la vida sirve también para la vida en todas sus etapas, para vivir el aquí y ahora.

En definitiva, elaborar las voluntades anticipadas, además de responder a unos criterios éticos sobre el final de la vida, es un acto de amor. Un acto de amor, sí, que penetra los últimos suspiros del amor responsable a la vida.

\section{Acompañar en el duelo}

En efecto, el duelo es esa experiencia de dolor, lástima, aflicción o resentimiento que se manifiesta de diferentes maneras con ocasión de la pérdida de algo o alguien con valor significativo.

Hay diferentes tipos de duelo (Bermejo, 2003). Vivimos un duelo anticipatorio antes de que la pérdida se produzca, que, en la mayoría de los casos, contribuye a prepararse a la misma. Vivimos un impacto normal en el momento de la pérdida, que dura un tiempo diferenciado según cada persona y el valor de lo perdido (duelo normal). Otras personas tardan en reaccionar en su vivencia y manifestación del dolor y hablamos entonces de duelo retardado. No falta quien no consigue colocar dentro de sí la propia historia y puede caer en un duelo crónico o incluso patológico.

En todo caso, el duelo por la pérdida de un ser querido es un indicador del amor hacia la persona fallecida. No hay amor sin duelo. Alguien tiene que perder al otro, antes o después. Se diría que, por doloroso que resulte, forma parte de la condición humana. Incluso, por extraño que pudiera parecer decirlo, si la muerte no nos arrancara a los seres queridos, si viviéramos indefinidamente, la vida perdería su color, moriría la solidaridad ante la vulnerabilidad ajena, la eternidad nos quitaría sabor a las experiencias humanas que lo tienen también por ser finitas, limitadas, mortales.

Pero no es la razón precisamente la instancia que más nos ayuda en los momentos de dolor por la pérdida de un ser querido, aunque a veces pareciera que lo deseáramos y que pretendiéramos hacernos estoicos e intentar consolarnos con argumentos en lugar de con afectos. Nunca, en el dolor por la pérdida de un ser querido, alcanzará ningún razonamiento ni ninguna frase, por bien intencionada que sea dicha, el valor y la densidad de un signo que exprese cercanía y afecto, comunión y acompañamiento en el sentimiento -cualquiera que sea- que se vive.

M. Klein (1994) dice que el proceso de elaboración del duelo significa reinstalar dentro de uno mismo a los seres queridos, darles una presencia interna en la que el ser perdido no sea un perseguidor interior que genere culpa, sino buen recuerdo, con la dosis correspondiente de melancolía que Freud (2002) nos ayudó a comprender que va asociada al duelo.

Algunos autores (Avia y Vázquez, 1999; Ochoa de Alda, 2002) han investigado sobre la existencia de duelos no resueltos detrás de enfermedades psiquiátricas y problemas de salud en general, constatando que no son pocos los casos en los que estos trastornos son indicadores de pérdidas significativas que no han sido afrontadas con la suficiente atención. El duelo aumenta, pues, la morbilidad física y psiquiátrica.

Mi experiencia me dice también que detrás de personas en situación de exclusión y marginación se encuentran, con frecuencia, experiencias de duelo no vivido sanamente. En la historia de transeúntes, personas sin techo, drogodependientes y otros muchos colectivos particularmente vulnerables, fácilmente hay pérdidas no elaboradas.

Un buen acompañamiento en el duelo tiene, por tanto, una valencia preventiva. Pero no solo. Quizás una sociedad pueda juzgar su grado de humanidad también por el modo como afronta el duelo. En él se percibirá si lo esconde, lo privatiza, lo niega, o si por el contrario lo socializa, lo comparte, lo expresa y aprovecha de él a la búsqueda del sentido del vivir.

No podemos amar sin dolernos. El duelo es un indicador de amor, como el modo de vivirlo lo es también de la solidaridad y del reconocimiento de nuestra limitación y disposición al diálogo. De igual manera que hay duelos mal elaborados en la raíz de situaciones de enfermedad y de exclusión y marginación, hay también duelos que constituyen una oportunidad para reconstruir lazos que estaban rotos o debilitados, para 
aprender de nuevas relaciones, para dejarse cuidar y querer, para cultivar el sano recuerdo y darle el valor que tiene a la memoria, para reconocer el poder humanizador de las lágrimas y... del pañuelo.

La vocación de pañuelo en medio del duelo puede ser una manifestación de la disposición a caminar juntos en la oscuridad, siendo unos para otros, anclas que ofrezcan un poco de confianza en medio de la tempestad, símbolos de la esperanza, esa que es como la sangre que llevamos en las venas, que no se ve, pero sin la cual no hay vida.

El duelo apunta en el cuaderno de la vida una nota de verdad. No permite, como otras situaciones de la vida, un total ocultamiento. Reclama verdad. También por eso surgen dificultades relacionales entre familiares (y en otras ocasiones es ahí donde se resuelven), porque revela verdad, nuestra verdad más hermosa (el valor del amor) y nuestra verdad más trágica: la soledad radical y las tendencias egocéntricas e interesadas.

A quienes se despiden de su ser querido en el final de sus días bien les vendría esta fórmula: recapitular en pocas palabras el significado de cuanto vivido, expresar en clave de agradecimiento cuanto se ha compartido, entregado y recibido, y disposición a cultivar el recuerdo. Porque está claro que lo que es olvidado no puede ser sanado. Y el duelo reclama zurcir los rotos del corazón que se hacen con la pérdida, y aquellos otros descosidos que aparecen del pasado, sanando con paciencia, al hilo de la soledad y, en el mejor de los casos, de una buena compañía, la nueva vida.

Parece que en estos últimos años, junto con la tendencia a negar la muerte, manifestada de múltiples maneras (desde el cambio de escenario -la muerte institucionalizada-, hasta los profesionales del ocultamiento de la muerte maquillando los cadáveres -tanatopractores-, etc.) estamos asistiendo a algunos signos de retorno de la muerte antes negada. Quizás no tanto en la práctica cuanto en la reflexión.

La literatura le está dando un espacio cada vez más abierto a la muerte. Los problemas éticos del final de la vida son de interés para los medios de comunicación. La medicina paliativa, con sus implicaciones prácticas -nuevas unidades hospitalarias o centros de cuidados paliativos, asociaciones a nivel estatal o autonómico, programas de asistencia domiciliar, etc.) son signo de una cierta aceptación de la muerte y de la decisión de salir al paso de la posible deshumanización de la misma despersonalizándola por sobredosis de tecnología.

En efecto, la muerte ajena puede humanizarnos. El poeta Rilke (2005), en el "Libro de la pobreza y de la muerte", empieza señalando que muchos no saben morir, que no llegan a madurar y a elaborar su propia muerte, por lo que su vida les es arrebatada desde fuera, muriendo de una muerte en serie, que nada tiene que ver con ellos. Mientras que el anonimato y la banalidad convierten en horrorosa la muerte ajena, la muerte propia se constituye como el objetivo de toda la vida, que se tensa como un arco hacia ese momento de máxima intensidad vital que es la muerte propia.

El poeta aboga por vivir la propia muerte como posibilidad humana de ser sí mismo hasta el final. Rilke (2005) explica también por qué nos es dada la posibilidad de morir nuestra muerte propia. Justo porque hay en nosotros algo eterno, nuestra muerte no es similar a la animal.... Exactamente en la medida en que hay algo de eternidad en nosotros, podemos elaborar y trabajar nuestra propia muerte, lo que nos distingue radicalmente del resto de los animales. Pero ocurre que no sabemos hacerlo y que traicionamos nuestra más alta vocación, de manera que nuestra muerte no llega a vivirse siempre dignamente.

En la medida en que la muerte es vivida y no negada, el duelo es no solo más fácil de elaborar, sino que se puede convertir en una experiencia de crecimiento y humanización. Vivir la propia muerte consiste en elaborar sanamente el duelo anticipatorio, en hacer de la experiencia de pérdidas una oportunidad para buscar sentido en las relaciones interpersonales y en los valores que pueden cualificar el mismo hecho de perder.

En el ser humano, al dolor de la pérdida, precio del amor, se une la conciencia de la pérdida. Lewis, en Una pena en observación, mientras elabora la pérdida de su amada, relata:

Permanezco despierto toda la noche con dolor de muelas, dándole vueltas al dolor de muelas y al hecho de estar despierto. Esto también se puede aplicar a la vida. Gran parte de una desgracia cualquiera consiste, por así decirlo, en la sombra de la desgracia, en la reflexión sobre ella. Es decir, en el hecho de que no se limite uno a sufrir, sino que se vea obligado a seguir considerando el hecho de que sufre. Yo cada uno de mis días interminables no solamente lo vivo en pena, sino pensando en lo que es vivir en pena un día detrás de otro. (Lewis, 1994, pp.17-18). 
En la elaboración del duelo, no es infrecuente el sentimiento de culpa. No solo por cómo fue vivida la relación y por aquellas áreas oscuras que pudo haber en la misma, sino también por cómo se vivió la última etapa, experiencia que puede ser especialmente significativa y quedarse grabada intensamente en el recuerdo del superviviente. De ahí la importancia de promover un acompañamiento basado en la autenticidad de las relaciones, favoreciendo una muerte apropiada.

El sentimiento de culpa puede permanecer incluso más tiempo, hasta experimentarse culpa incluso por estar superando el duelo.

A veces, es tan fuerte esta tendencia a consolar que se llega a una evidente situación de ridículo en la relación con el enfermo terminal. Así, narra Kant:

Un médico no hacía sino consolar a su enfermo todos los días con el anuncio de la próxima curación, hoy diciéndole que el pulso iba mejor, mañana que lo que había mejorado era la excreción, pasado que el sudor era más fresco, etc. El enfermo recibe la visita de un amigo: ¿cómo va esa enfermedad?, le pregunta nada más entrar. ¡Cómo ha de ir! ¡Me estoy muriendo de mejoría! (Kant, 1979 , p.118).

Igualmente, en el duelo es fácil encontrar este tipo de frases superficiales en clave de exhortación. Algunas que todos reconoceremos como más o menos frecuentes son: "Trata de olvidar; mejor así; ahora es más feliz en el cielo; Dios lo ha querido; sólo los buenos se mueren jóvenes; Dios lo necesitaba; echa una losa sobre el pasado; mantente fuerte por los niños; suerte que tienes otros hijos", etc.

Elaborar el duelo supone no solo integrar la pérdida, asumir la desaparición del ser querido, aceptar que murió, sino también integrar la propia mortalidad, cuya conciencia se hace más patente con ocasión de la muerte de la persona querida. También hay muerte, pues, en los supervivientes. Como expresa San Agustín (2013), no solo se hace luto por la muerte de los seres queridos sino también debido a la toma de conciencia de la propia muerte.

La escucha es la herramienta con la que matar la muerte social, la soledad. En la película Johnny cogió su fusil (Campbell y Trumbo, 1971), en la que se narra la vida de un soldado que pierde los brazos, las piernas, la vista, el oído y la boca, pero que conserva la percepción por las sensaciones de la piel y las vibraciones, así como la lucidez mental, es interesante notar cómo la elaboración del duelo por las pérdidas acumuladas solo puede ser acompañada significativamente a partir de la creatividad de quien está dispuesta a escuchar lo que no se dice, pero se puede -con un arte especial- descifrar porque llega por diferentes canales de comunicación no verbal. De hecho, una de sus lamentaciones es la de no ser escuchado, aunque en realidad no puede hablar. En efecto, así como comunicar es mucho más que hablar, escuchar es mucho más que oír.

El recuerdo es el presente del pasado. Cuando un ser querido muere, nos queda el recuerdo. Es más que la memoria. La memoria es una propiedad común al hombre y al animal, mientras que el reconocimiento de eventos pasados en cuanto pasados es propiedad exclusiva del hombre.

También el recuerdo puede constituir un gran tesoro y puede ser terapéutico si bien utilizado. Puede cubrir el vacío generado por la pérdida constituyendo el presente de lo que fue y ya no es. Invitar a olvidar en la elaboración del duelo no es la indicación más adecuada. Quien no consigue, por otra parte, hacer que el recuerdo no pase a ser una obsesión, probablemente necesite ayuda profesional. Es normal, en todo caso, que en los primeros momentos el recuerdo se imponga con sus leyes y los sueños cumplan también su función adaptativa a la nueva situación de pérdida.

Séneca, en las Cartas a Lucilio (2018) habla del recuerdo en estos términos como guardián del propio dolor haciendo referencia a que cuanto más lo sientes antes se digiere y que el objetivo tiene que ver con pasar de un recuerdo doloroso a nostálgicamente agradable.

Acompañar a recordar sanamente supone, una vez más, dar espacio a la narración del pasado, de su significado, utilizando la evocación de hechos, de imágenes, utilizando objetos, fotografías, etc., que contribuyan a colocar al difunto en un lugar adecuado del corazón, donde no haga daño, donde constituya, como tal recuerdo un valor del presente.

La literatura de Grecia y de Roma clásicas desarrolló el consuelo como un conjunto de argumentos que se ofrecían al doliente en forma de simples cartas o de tratados filosóficos. Del conjunto de los argumentos que se utilizaban, eran frecuentes los que hacían referencia al hecho de que todos los hombres son mortales, que lo 
importante no es haber vivido mucho sino virtuosamente, que el tiempo cura todas las heridas, que lo perdido era sólo prestado, que el que lloramos no sufre, etc. Eran lugares comunes a los que a veces se añadían elogios del muerto y ejemplos de hombres que sobrellevaron la desgracia con valor.

Este tipo de consuelo se presentaba poniendo, normalmente, a la razón como consolador supremo. No obstante, Séneca considera el cariño de la familia principal fuente de apoyo. Y los viejos consoladores cristianos, aún recurriendo a argumentos paganos, pudieron renovar el género por la importancia que daban a la emoción y por las fuentes de su inspiración, que eran a la vez bíblicas, éticas y místicas.

Hoy estamos lejos de la tradición estoica, seguida por Cicerón, que concibe los sentimientos y las emociones como desórdenes del alma y a las personas por ellos afectadas, poco prudentes y sabias. Pero quizá no estamos todavía tan lejos de la tradición que llevaba a consolar con frases hechas.

El afecto sincero, comunicado entrañablemente con nuestros sentidos, mucho más que la razón, serán el camino más apropiado para acompañar a quien vive la pérdida de un ser querido y elabora el dolor por la misma.

Los profesionales de la salud, formados suficientemente en psicología, particularmente en counselling, contribuirán a prevenir numerosos duelos complicados y patológicos si acompañan procesos saludables al final de la vida de los seres queridos. El counselling, en este sentido, tiene un gran poder preventivo.

\section{Referencias}

Avia, D. y Vázquez, C. (1999). Optimismo inteligente. Madrid, España: Alianza Editorial.

Barrio, I. M., y Simon, P. (2009). Testamento vital. En J. C. Bermejo y F. Álvarez, Diccionario de Pastoral de la Salud y Bioética (pp. 1746-1750). Madrid, España: San Pablo.

Beauchamp, T. L., y Childress, J. F. (1999). Principios de Ética Biomédica. Barcelona, España: Masson.

Bermejo, J. C., Villacieros, M. y Carabias, R. (2013). Diseño y fiabilidad de una escala sobre la idea de empatía. Diferencias entre profesiones sanitarias y sociales. Acción Psicológica, 10(2), 143-156. https://doi. org/10.5944/ap.10.2.12217

Bermejo, J. C. (2009). Estoy en duelo. Madrid, España: PPC.

Bermejo, J. C. (Ed). (2003). La muerte enseña a vivir. Vivir sanamente el duelo. Madrid, España: San Pablo.

Bermejo, J. C. y Magaña, M. (2014). “Modelo Humanizar” de intervención en duelo. Madrid, España: Sal Terrae.

Bermejo, J. C., (2009). Sanar el morir. En J. L. Cabria, Fichas sobre la muerte y el morir (pp. 120-122). Burgos, España: Monte Carmelo.

Bermejo, J. C., Carabias, R. y Villacieros, M. (2012). Efecto de un curso de relación de ayuda sobre la elección de respuesta espontánea e identificación de respuesta empática en alumnos de enfermería. Gerokomos, 23(1), 216-221. https://doi.org/10.4321/S1134-928X2012000100005

Bermejo, J. C., Magaña, M., Villacieros, M., Carabias, R. y Serrano, I. (2012). Estrategias de afrontamiento y resiliencia como factores mediadores de duelo complicado. Revista de Psicoterapia, 88, 85-95.

Bermejo, J. C., Villacieros, M. y Magaña, M. (2017). Perfil, motivación, satisfacción y compromiso de un voluntariado de acompañamiento en duelo. Propiedades psicométricas de los cuestionarios Organizational Commitment Cuestionnarie y Job Diagnostic Survey. Medicina Paliativa, 4(1), 4-13. https://doi.org/10.1016/j.medipa.2014.05.003

Bermejo, J.C. y Belda, R. M. (2011). Testamento vital. Diálogo sobre la vida, la muerte y la libertad. Madrid, España: PPC.

Bover, A., Santancreu, E., Pons, V., Mestre, J. M, Gallo, J. y Adrover, R. (2002). Claudicación familiar de los ancianos ingresados en una residencia. Revista Multidisciplinar de Gerontología, 12(4), 198-202.

Campbell, B. (Productor) y Trumbo, D. (Director) (1971). Johnny cogió su fusil [Película]. Estados Unidos: Cinemation Industries.

Freud, S. (2002). Totem y tabú. Los instintos y sus destinos. Duelo y melancolía. Barcelona, Madrid, España: RBA.

Gómez Sancho, M. (2005). Morir con Dignidad. Madrid, España: Aran Ediciones. 
Gonzalos, O. A. y Magos, M. (2012). La dinámica familiar como génesis de la codependencia. Revista de Psicología, 3(1), 263-281.

Kant, I. (1979). Si el género humano se halla en progreso constante hacia mejor. En Filosofía de la historia (pp. 95-122). México D. F., México: FCE.

Klein, M. (1994). Amor, Culpa y Reparación y Otros Trabajos. En Obras Completas (Vol. I). Barcelona, España: Paidós Ibérica.

Lewis, C. S. (1994). Una pena en observación. Barcelona, Madrid, España: Anagrama.

Ley 41/2002, de 14 de noviembre, básica reguladora de la autonomía del paciente y de derechos y obligaciones en materia de información y documentación clínica. Boletín Oficial del Estado (España), 274, de 15 de noviembre de 2002.

Malherbe, J. F. (1993). Hacia una ética de la Medicina. Santafé de Bogotá, Colombia: San Pablo.

Marcos del Cano, A. M. (2001). La toma de decisiones al final de la vida: el testamento vital y las indicaciones previas. Moralia, 24, 491-518.

Maslach, C. (1982). The cost of coping. Nueva York, Estados Unidos: Prentice Hall Press.

Ochoa de Alda, I. (2002). Nuevas narrativas para afrontar la muerte de un ser querido. Revista Cuadernos de Terapia familiar, 2(51), 123-131.

Rilke, R. M. (2005). El libro de horas. Madrid, España: Hiperión.

Sahni, V. (2016). The Lazarus phenomenon. Journal of the Royal Society of Medicine Open, 7(8) 1-6. https:// doi.org/full/10.1177/2054270416653523

San Agustín (2013). Obras completas de San Agustín, Vol. 4: Las confesiones. Madrid, España: BAC.

Sandrin, L. (2006). Testamento di vita o testamento di sfiducia? Camillianum Roma, 18, 557-563.

Sandrin, L., Calduch-Benages, N. y Torralba F. (2007). Cuidarse a sí mismo. Para ayudar sin quemarse. Madrid: PPC.

Séneca, L. A. (2018). Cartas a Lucilio, Libro VII, Carta LXIII. Barcelona, España: Ariel.

Stenberg, U., Ruland, C. M. y Miaskowski, C. (2010). Review of the literature on the effects of caring for a patient with cancer. Psychooncology, 19, 1013-1025. https://doi.org/10.1002/pon.1670

Tolstoi, L. (1970). La muerte de Ivan Ilich. Estella, España: Salvat.

Villacieros, M., Olmos, R. y Bermejo, J. C. (2017). The Empathic Process and Misconceptions that Lead to Burnout in Healthcare Professionals. The Spanish Journal of Psychology, 20, E68. htpps://doi.org/10.1017/ sjp.2017.66

Artículo recibido: 16/01/2019

Artículo aceptado: 13/02/2019 